\title{
Coronary flow reserve is supranormal in endurance athletes: an adenosine transthoracic echocardiographic study
}

\author{
D J R Hildick-Smith, P J Johnson, C R Wisbey, E M Winter, L M Shapiro
}

\begin{abstract}
Objective-To compare coronary flow reserve in endurance athletes and healthy sedentary controls, using adenosine transthoracic echocardiography.

Methods-29 male endurance athletes (mean (SD) age 27.3 (6.6) years, body mass index (BMI) $22.1(1.9) \mathrm{kg} / \mathrm{m}^{2}$ ) and 23 male controls (age 27.2 (6.1) years, BMI $23.9(2.6) \mathrm{kg} / \mathrm{m}^{2}$ ) with no coronary risk factors underwent transthoracic echocardiographic assessment of distal left anterior descending coronary artery (LAD) diameter and flow, both at rest and during intravenous adenosine infusion $(140 \mu \mathrm{g} / \mathrm{kg} / \mathrm{min})$.

Results-Distal LAD diameter and flow were adequately assessed in 19 controls (83\%) and 26 athletes $(90 \%)$. Distal LAD diameter in athletes $(2.04(0.25) \mathrm{mm})$ was not significantly greater than in sedentary controls $(1.97(0.27) \mathrm{mm})$. Per cent increase in LAD diameter following $400 \mu \mathrm{g}$ sublingual nitrate was greater in the athletes than in the controls, at $14.1(7.2) \% v 8.8(5.7) \%$ $(\mathrm{p}<0.01)$. Left ventricular mass index in athletes exceeded that of controls, at $130(19) v 98$ (14) $\mathrm{g} / \mathrm{m}^{2}$ ( $\left.\mathrm{p}<0.01\right)$. Resting flow among the athletes $(10.6(3.1) \mathrm{ml} / \mathrm{min} ; 4.4(1.2) \mathrm{ml} / \mathrm{min} / 100 \mathrm{~g}$ left ventricular mass) was less than in the controls $(14.3(3.6) \mathrm{ml} / \mathrm{min} ; 8.2(2.2) \mathrm{ml} / \mathrm{min} / 100 \mathrm{~g}$ left ventricular mass) (both $\mathrm{p}<0.01)$. Hyperaemic flow among the athletes $(61.9(17.8) \mathrm{ml} / \mathrm{min})$ exceeded that of the controls $(51.1(14.6) \mathrm{ml} / \mathrm{min} ; \mathrm{p}=0.02)$, but not when corrected for left ventricular mass (25.9 (5.6) v $28.5(7.4) \mathrm{ml} / \mathrm{min} / 100 \mathrm{~g}$ left ventricular mass; NS). Coronary flow reserve was therefore substantially greater in the athletes than in the controls, at 5.9 (1.0) $v 3.7$ $(0.7)(\mathrm{p}<0.01)$.

Conclusions-Coronary flow reserve in endurance athletes is supranormal and endothelium independent vasodilatation is enhanced. Myocardial hypertrophy per se does not necessarily impair coronary flow reserve. Adenosine transthoracic echocardiography is a promising technique for the investigation of coronary flow reserve.

(Heart 2000;84:383-389)
\end{abstract}

Keywords: coronary flow reserve; athlete; adenosine transthoracic echocardiography

The concept of coronary flow reserve-the ratio of maximum to resting coronary arterial blood flow-was introduced to clinical practice by Gould and Lipscomb. ${ }^{1}$ It has since been used widely, both to assess epicardial coronary stenoses and to examine the integrity of the microvascular circulation. However, measurement of this ratio is limited by the techniques available. The gold standard-intracoronary Doppler ${ }^{2}$ - is invasive and therefore unsuited to the acquisition of serial measurements over time, or to the investigation of normal or healthy individuals.

Non-invasive imaging techniques such as magnetic resonance imaging and positron emission tomography are increasingly capable of measuring coronary flow reserve, ${ }^{3}$ but they are complex, time consuming, and expensive. Transoesophageal echocardiography also allows calculation of coronary flow reserve, though being a semi-invasive technique it is not suited to the investigation of normal subjects. Transthoracic echocardiography has been used to determine distal left anterior descending coronary artery diameter, ${ }^{6}$ flow, ${ }^{7}$ and more recently coronary flow reserve..$^{8-11}$ The noninvasive simplicity of this technique allows measurements to be made on a serial basis, and non-pathological conditions to be investigated.
One such condition in which coronary flow reserve is of interest is athletic training. Pathological left ventricular hypertrophy is known to impair coronary flow reserve $\mathrm{e}^{12-17}$ but the effects of physiological left ventricular hypertrophy on flow reserve are not known. Some animal studies have suggested that exercise training increases coronary sensitivity to vasoactive pharmacological agents, ${ }^{18-20}$ and augments maximum coronary flow in response to adenosine. ${ }^{182122}$ We therefore undertook to compare coronary flow reserve in endurance athletes with that in sedentary controls using adenosine transthoracic echocardiography.

\section{Methods}

SUBJECT SELECTION

Endurance athletes were recruited on a national basis. All participants were male, had competed at national or international level, and were actively training at the time of study. All underwent assessment of maximum oxygen consumption ( $\left.\dot{\mathrm{V}}_{2} \max \right)$, following a standard protocol using Douglas bags, ${ }^{23}$ to confirm their high performance athletic status. Sedentary controls were recruited locally and were excluded if they had participated in any exercise training programme during the preceding year. Some control subjects had also 


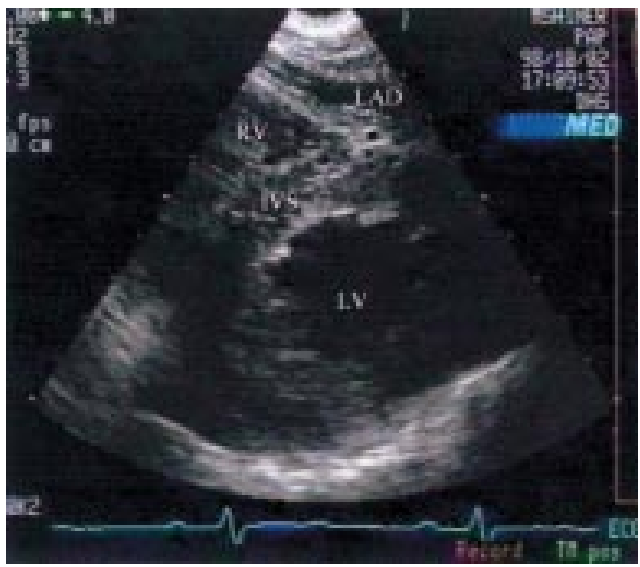

Figure 1 A low left parasternal short axis section through the left ventricle. The distal left anterior descending coronary artery is identified as a circular radiolucency with increased circumferential opacification lying in the anterior interventricular sulcus, barely $3 \mathrm{~cm}$ from the chest wall. IVS, interventricular septum; LAD, left anterior descending coronary artery; $L V$, left ventricle; $R V$, right ventricle.

been involved in the original feasibility study of coronary flow reserve. ${ }^{8}$ Participants were normotensive non-smokers with no history of hypercholesterolaemia and no family history of premature coronary disease. The study was approved by the local regional ethics committee and all participants gave written informed consent.

ECHOCARDIOGRAPHIC EQUIPMENT

Studies were undertaken using a Vingmed CFM 750 ultrasound unit (GE Vingmed Ultrasound, Trondheim, Norway). A $3.5 \mathrm{MHz}$ annular phased array transducer was used for cross sectional and $M$ mode analysis of interventricular septal thickness, end diastolic left ventricular dimension, and posterior wall thickness. Coronary imaging was performed with a broad bandwidth $5 \mathrm{MHz}$ transducer upgraded to $6.3 \mathrm{MHz}$ for maximum near field cross sectional resolution. Doppler frequency was $4 \mathrm{MHz}$.

TECHNIQUE

Subjects were asked to avoid caffeine containing products for the 12 hours before echocardiography. ${ }^{24}$ A venous cannula was sited and subjects were examined in the left lateral decubitus position using a low left parasternal window, as previously described. ${ }^{67}$ The left ventricle was imaged in short axis and the distal left anterior descending coronary artery (LAD) was identified as a circular radiolucency lying in epicardial fat in the anterior interventricular sulcus (fig 1). Magnified images were committed to videotape for off line analysis of LAD diameter.

Sublingual glyceryl trinitrate $400 \mu \mathrm{g}$ was given to dilate and fix the epicardial coronary diameter, preventing further flow induced vasodilatation. ${ }^{25}{ }^{26}$ Parasternal short axis cross sectional and $M$ mode images of the left ventricle were then recorded to allow off line caliper analysis of end diastolic interventricular septal thickness, posterior wall thickness, and internal ventricular diameter, according to the recommendations of the American Society of
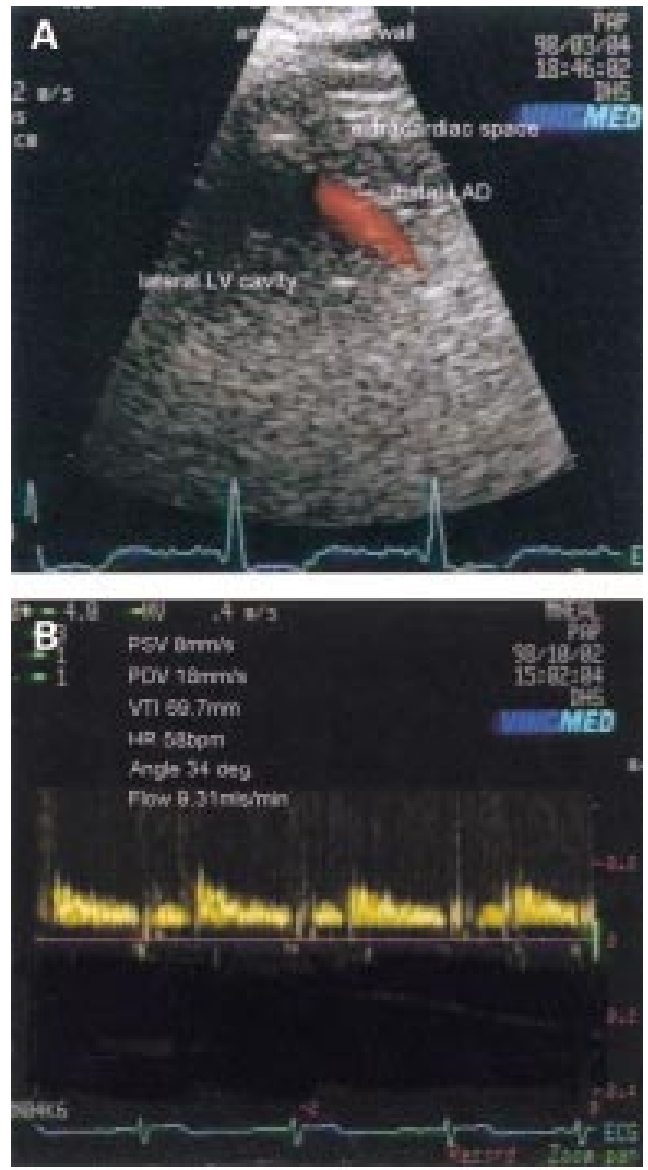

Figure 2 (A) Low left parasternal long axis window. Resting distal left anterior descending coronary artery (LAD) flow is visualised as a thin red diastolic flame once low velocity reject and frame rate are minimised.

(B) Spectral Doppler display of resting flow in the distal $L A D$ in an endurance athlete. HR, heart rate; PDV, peak diastolic velocity; PSV, peak systolic velocity; VTI, velocity-time integral.

Echocardiography, ${ }^{27}$ and to allow calculation of left ventricular mass according to the Penn convention. ${ }^{28}$ Five minutes after administration of glyceryl trinitrate, end diastolic distal LAD diameter was again recorded as above.

The ultrasound probe was then rotated anticlockwise $90^{\circ}$ and the probe base angled laterally and downwards to allow Doppler analysis of the anterior interventricular sulcus at the smallest possible incident angle. Magnified colour flow mapping of this region was undertaken. The LAD was identified as a thin red diastolic jet (fig 2A). Doppler sampler width was maximised within the colour signal, and flow was analysed with spectral Doppler (fig 2B). The incident angle at which the Doppler signal intersected LAD blood flow was noted with on line angle correction.

Intravenous adenosine was infused $(140 \mu \mathrm{g} /$ $\mathrm{kg} / \mathrm{min}$, right antecubital fossa) for a maximum of six minutes. Colour flow mapping of the distal LAD revealed disturbed flow (fig 3A). Pulsed wave Doppler analysis of hyperaemic LAD flow was recorded as above (fig 3B). During the final minute of infusion, LAD diameter was again recorded in short axis to exclude further flow induced vasodilatation. ${ }^{29}$ 

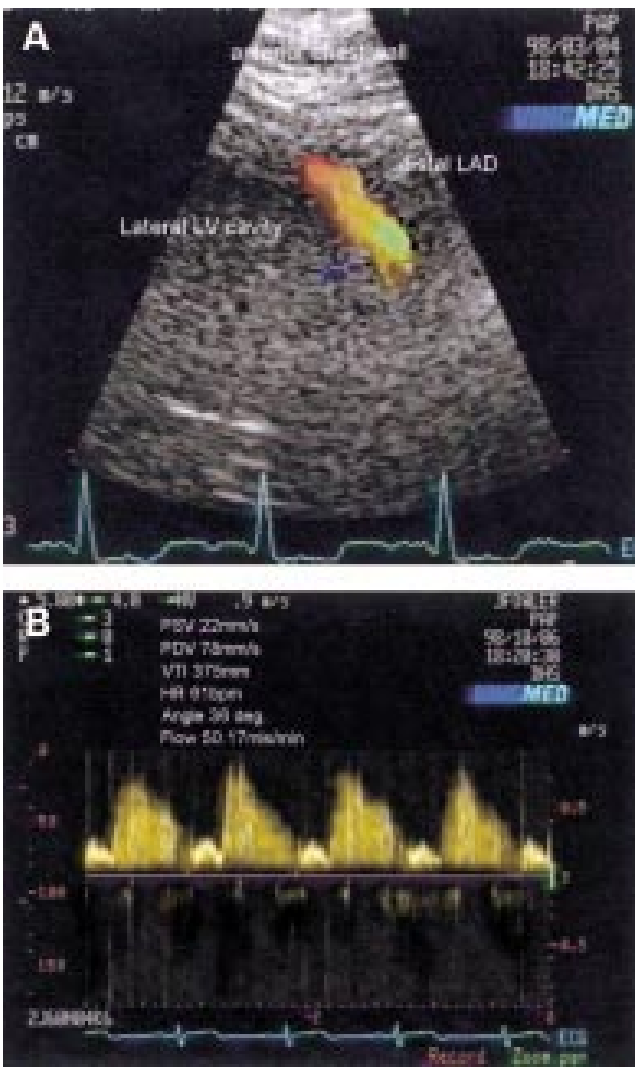

Figure 3 (A) Magnified colour flow mapping of hyperaemic distal left anterior descending coronary artery (LAD) flow. (B) Spectral Doppler trace of hyperaemic distal LAD blood flow (note scale alteration). HR, heart rate; PDV, peak diastolic velocity; PSV, peak systolic velocity; VTI, velocity-time integral.

DATA COLLECTION

The Vingmed CFM 750 incorporates an internal analysis package for use with video playback. Distal LAD diameter was measured at end diastole with internal calipers applied to endothelial borders; therefore intraluminal diameter was gauged as previously validated..$^{30}$ Peak velocities were read with spectrum calipers. Velocity-time integral was computed from manually acquired envelope tracings of the Doppler signal over complete cardiac cycles. A mean of three measures was calculated for LAD diameter, flow velocity, and velocity-time integral. Heart rate was calcu-

Table 1 Reproducibility, interobserver variability, and intraobserver variability

\begin{tabular}{lllc}
\hline Variable & $\begin{array}{l}\text { Interobserver } \\
\text { variability (\%) }\end{array}$ & $\begin{array}{l}\text { Intraobserver } \\
\text { variability (\%) }\end{array}$ & $\begin{array}{l}\text { Reproducibility } \\
\text { (\%) }\end{array}$ \\
\hline LAD diameter (mm) & 3.7 & 3.2 & 4.1 \\
IVST (mm) & 3.3 & 2.2 & 3.6 \\
LVID (mm) & 3.5 & 3.1 & 4.3 \\
PWT (mm) & 4.6 & 3.5 & 4.8 \\
LVM (g) & 5.1 & 4.5 & 6.1 \\
Resting peak diastolic velocity (m/s) & 4.7 & 2.8 & 5.8 \\
Resting velocity-time integral (mm) & 3.7 & 3.0 & 3.8 \\
Resting LAD flow (ml/min) & 5.5 & 4.1 & 6.8 \\
Resting LAD flow (ml/min/100 g LV) & 5.8 & 4.8 & 7.5 \\
Hyperaemic peak diastolic velocity (m/s) & 5.0 & 4.1 & 14.1 \\
Hyperaemic velocity time integral (mm) & 3.9 & 3.6 & 8.2 \\
Hyperaemic LAD flow (ml/min) & 6.5 & 4.5 & 7.8 \\
Hyperaemic LAD flow (ml/min/100 g LV) & 6.7 & 5.1 & 9.1 \\
Coronary flow reserve & 5.8 & 3.8 & \\
\hline
\end{tabular}

IVST, interventricular septal thickness; LAD, left anterior descending coronary artery; LV, left ventricle; LVID, left ventricular internal diameter; LVM, left ventricular mass; PWT, posterior wall thickness. lated from $\mathrm{RR}$ intervals of simultaneously recorded ECGs.

MEASUREMENTS AND CALCULATIONS

Velocity distribution within a given cross section of a cylinder is parabolic. ${ }^{31}$ Mean velocity is therefore half maximum velocity. ${ }^{31}$ In the original validation of coronary Doppler flow wires peak velocities were therefore corrected by a factor of 0.5 for volumetric flow calculations. ${ }^{32}$ This correction factor has been adopted by subsequent investigators in the assessment of coronary flow ${ }^{43}$ and was used throughout this study.

- Body surface area (BSA) was calculated from height and body mass measurements according to the formula of $\mathrm{Du}$ Bois and $\mathrm{Du}$ Bois $^{34}$ : height $(\mathrm{cm})^{0.725} \times$ mass $(\mathrm{kg})^{0.425} \times$ 0.007184 .

- Body mass index (BMI) was calculated as mass $(\mathrm{kg}) / \mathrm{h}$ eight $(\mathrm{m})^{2}$.

- Diastolic interventricular septal thickness, posterior wall thickness, and internal ventricular diameter were measured according to the recommendations of the American Society of Echocardiography. ${ }^{27}$

- Left ventricular mass (LVM) was calculated according to the Penn convention ${ }^{28}$ : left ventricular mass $=1.04((\mathrm{LVID}+\mathrm{PWT}+$ $\left.\mathrm{IVST}^{3}-\mathrm{LVID}^{3}\right)-13.6 \mathrm{~g}$, where LVID $=$ left ventricular internal diameter, PWT = posterior wall thickness, and IVST $=$ interventricular septal thickness.

- Left ventricular mass index (LVMI) was calculated as LVM/BSA.

- Left ventricular hypertrophy was defined according to Devereux's criteria ${ }^{35}$ as LVMI $>134 \mathrm{~g} / \mathrm{m}^{2}$ in men and $>110 \mathrm{~g} / \mathrm{m}^{2}$ in women.

- Flow calculations were made according to the method of Doucette and colleagues. ${ }^{32}$ Coronary flow was calculated as: $\mathrm{F}=\pi(\mathrm{d} /$ $2)^{2} \times \mathrm{HR} \times \mathrm{VTI} \times 1 / \cos \theta \times 0.5$, where $\mathrm{F}=$ flow $(\mathrm{ml} / \mathrm{min}) ; \mathrm{d}=$ distal LAD diameter $(\mathrm{cm}) ; \mathrm{HR}=$ heart rate $($ beats $/ \mathrm{min}) ; \mathrm{VTI}=$ velocity-time integral $(\mathrm{cm})$; and $\cos \theta=$ cosine incident angle of Doppler beam.

- Coronary flow reserve was calculated as: $\mathrm{CFR}=\mathrm{F}^{\mathrm{h}} / \mathrm{F}^{\mathrm{b}}$, where CFR = coronary flow reserve; $\mathrm{F}^{\mathrm{h}}=$ hyperaemic coronary flow; and $\mathrm{F}^{\mathrm{b}}=$ baseline coronary flow.

VARIABILITY

Reproducibility of the technique, interobserver variability, and intraobserver variability were assessed. Intraobserver variability was assessed from 15 studies, with the observer blinded to previous echocardiographic data. For the assessment of interobserver variability, 15 ultrasound studies were examined independently by the unit's senior echocardiographic technician, blinded to prior echocardiographic data. Reproducibility was assessed in five participants who underwent repeat adenosine echocardiography on a separate date. Data for reproducibility, intraobserver variability, and interobserver variability are shown in table 1 . They were calculated as the standard deviation of the difference between the two measure- 
Table 2 Comparative characteristics of endurance athletes and sedentary controls

\begin{tabular}{llll}
\hline Variable & Athletes & Controls & p Value \\
\hline Age (years) & $27.3(6.6)$ & $27.2(6.1)$ & $\mathrm{NS}$ \\
$\mathrm{BSA}\left(\mathrm{m}^{2}\right)$ & $1.87(0.11)$ & $1.87(0.11)$ & $\mathrm{NS}$ \\
$\mathrm{BMI}\left(\mathrm{kg} / \mathrm{m}^{2}\right)$ & $22.1(1.9)$ & $23.9(2.6)$ & 0.01 \\
IVST $(\mathrm{mm})$ & $10.8(0.9)$ & $9.3(0.9)$ & $<0.01$ \\
LVID $(\mathrm{mm})$ & $53.5(3.4)$ & $49.0(2.7)$ & $<0.01$ \\
PWT $(\mathrm{mm})$ & $9.9(1.0)$ & $9.2(0.9)$ & 0.02 \\
LVM $(\mathrm{g})$ & $252(35)$ & $178(27)$ & $<0.01$ \\
LVMI $\left(\mathrm{g} / \mathrm{m}^{2}\right)$ & $135(19)$ & $95(14)$ & $<0.01$ \\
Angle correction & $35(8)$ & $39(9)$ & $\mathrm{NS}$ \\
Distal LAD diameter (mm) & $2.04(0.25)$ & $1.98(0.27)$ & $\mathrm{NS}$ \\
Distal LAD diameter post-GTN & $2.33(0.33)$ & $2.15(0.28)$ & $\mathrm{NS}(0.06)$ \\
Diameter increase post-GTN $(\%)$ & $14.1(7.2)$ & $8.8(5.7)$ & 0.01 \\
\hline
\end{tabular}

Values are mean (SD).

BMI, body mass index; BSA, body surface area; GTN, glyceryl trinitrate; IVST, interventricular septel thickness; LAD, left anterior descending coronary artery; LVID, left ventricular internal diameter; LVM, left ventricular mass; LVMI, left ventricular mass index; PWT, posterior wall thickness.

ments divided by the mean measurement and expressed as per cent of the mean.

STATISTICS

Data distribution was assessed. Within group comparisons were made with the paired Student's $t$ test. Between group comparisons were made with the unpaired Student's $t$ test. Measurements are given as mean (SD) unless otherwise indicated. Significance was accepted at $\mathrm{p}<0.05$.

\section{Results}

Twenty nine male endurance athletes and 23 sedentary male controls were recruited to the study. Subject characteristics are shown in table 2. Of the athletes, 24 were engaged in middle to long distance running (between $800 \mathrm{~m}$ and marathon distance) and five were rowers. Duration of intensive training was greater than three years in all athletes, and all were engaged in active training at the time of the study. Mean $\dot{\mathrm{V}}_{2} \max$ among the athletes was $71.7(4.6) \mathrm{ml} / \mathrm{kg} / \mathrm{min}$.

ECHOCARDIOGRAPHY

Cross sectional and $M$ mode left ventricular images were adequate in all subjects to allow measurement of interventricular septal thickness, left ventricular internal diameter, and posterior wall thickness, and to allow calculation of left ventricular mass. Twelve athletes $(46 \%)$ and none of the sedentary controls had left ventricular hypertrophy by echocardiographic criteria (left ventricular mass index $>134 \mathrm{~g} / \mathrm{m}^{2}$ ).

The distal LAD was adequately imaged in cross section in 20 sedentary controls (87\%) and 27 athletes (93\%). LAD flow was ad- equately imaged by spectral Doppler in 19 controls (83\%) and 27 athletes (93\%). One athlete showed no response to adenosine (see below) and was excluded from further analysis. Paired data were therefore available for 26 athletes and 19 controls.

Subject characteristics, left ventricular indices, and distal LAD diameter measurements are shown in table 2. Ventricular mass and volume were substantially greater among the athletes. Distal LAD diameter was no greater than in the controls. Per cent diameter increase in response to $400 \mu \mathrm{g}$ sublingual glyceryl trinitrate was, however, significantly greater in the athletes than in the controls.

\section{RESPONSE TO ADENOSINE}

Adenosine infusion was tolerated well. No participant requested early termination of the infusion. One athlete developed asymptomatic transient second degree heart block. In one athlete there was no response to adenosine infusion, which has been noted before ${ }^{3637}$ though the mechanism remains unknown. Data relating to this athlete were therefore excluded from subsequent analysis.

Resting and hyperaemic data in athletes and controls are shown in table 3. At rest, heart rate, peak systolic and diastolic velocities, velocity-time integral, and distal LAD flow were all less in the athletes than in the controls. During hyperaemia, peak diastolic velocity, velocity-time integral, and distal LAD flow were all greater among the athletes, while heart rate remained lower. Coronary flow reserve was therefore supranormal in athletes in comparison with controls, at 5.9 (1.0) v 3.7 (0.7). Coronary flow reserve in athletes with $(\mathrm{n}=12)$ and without $(n=14)$ left ventricular hypertrophy did not differ significantly, at $6.0(0.9)$ v 5.9 (1.2), respectively.

\section{Discussion}

We found that coronary flow reserve in endurance athletes is supranormal: resting coronary flow is lower than in sedentary controls while hyperaemic coronary flow is greater. Scaled for left ventricular mass, resting coronary flow remained lower in endurance athletes, while hyperaemic coronary flow was similar to that of controls. The physiological significance of these findings is not clear, but it is likely to reflect the greater efficiency of the exercise trained heart. ${ }^{2138-40}$

Table 3 Comparison of distal left anterior coronary artery diameter, flow velocities, and flow reserve between endurance athletes and sedentary controls

\begin{tabular}{|c|c|c|c|c|c|c|}
\hline \multirow[b]{2}{*}{ Variable } & \multicolumn{3}{|l|}{ Resting } & \multicolumn{3}{|l|}{ Hyperaemic } \\
\hline & Athletes & Controls & p Value & Athletes & Controls & $p$ Value \\
\hline PSV $(\mathrm{m} / \mathrm{s})$ & $0.06(0.08)$ & $0.11(0.04)$ & 0.02 & $0.27(0.25)$ & $0.21(0.19)$ & NS \\
\hline $\mathrm{PDV}(\mathrm{m} / \mathrm{s})$ & $0.18(0.06)$ & $0.27(0.08)$ & $<0.01$ & $0.90(0.20)$ & $0.77(0.19)$ & 0.02 \\
\hline VTI (mm) & $90(21)$ & $117(26)$ & $<0.01$ & $432(83)$ & $364(62)$ & $<0.01$ \\
\hline Heart rate (beats/min) & $56.5(7.9)$ & $68.7(8.8)$ & $<0.01$ & $68.4(13.7)$ & $77.5(10.4)$ & 0.02 \\
\hline Flow $(\mathrm{ml} / \mathrm{min})$ & $10.6(3.1)$ & $14.3(3.6)$ & $<0.01$ & $61.9(17.8)$ & $51.1(14.6)$ & 0.02 \\
\hline Flow (ml/min/100 g) & $4.4(1.2)$ & $8.2(2.2)$ & $<0.01$ & $25.9(5.6)$ & $28.5(7.4)$ & NS \\
\hline Coronary flow reserve & - & - & - & $5.9(1.0)$ & $3.7(0.7)$ & $<0.01$ \\
\hline
\end{tabular}

Peak systolic velocity (PSV), peak diastolic velocity (PDV), and velocity-time integral (VTI) are angle corrected values. 
HUMAN STUDIES

There are only four previous studies of coronary flow in athletes. ${ }^{41-44}$ Heiss and colleagues compared 11 athletes with 11 untrained students ${ }^{41}$ using argon clearance. They found coronary flow to be lower in trained athletes, both at rest and during exercise. The exercise protocol, however, was submaximal, and the argon clearance technique has subsequently been found to underestimate hyperaemic flow. ${ }^{45}$ Haskell and colleagues performed coronary angiography on 11 ultradistance runners and 11 controls with atypical chest pain. ${ }^{42}$ In contrast to other investigators, ${ }^{46-49}$ they found proximal coronary dimensions to be no greater in athletes than in controls. However, coronary dilating response to glyceryl trinitrate was significantly greater in the athletes, implying enhanced endothelium independent vasodilator capacity, as has been shown in exercise trained pigs. ${ }^{19}$ Our study corroborates this observation. Radvan and colleagues undertook a study of coronary flow reserve using positron emission tomography in 10 rowers and 10 patients with hypertrophic cardiomyopathy. ${ }^{43}$ They found resting coronary flow (per gram left ventricular muscle mass) did not differ significantly between athletes and patients, but that vasodilator reserve in response to intravenous dipyridamole was significantly attenuated in the patients with hypertrophic cardiomyopathy. Recently, Toraa and associates assessed coronary flow reserve in athletes, using positron emission tomography. ${ }^{44}$ They found that total resting coronary flow was similar in athletes and controls, and calculated a coronary flow reserve of 6.1 in athletes and 3.8 in controls.

ANIMAL STUDIES

Studies of coronary flow in exercise trained animals offer conflicting results. Resting coronary flow per unit left ventricular mass has been described as lower, ${ }^{38}$ the same, ${ }^{22}{ }^{50}$ or greater $^{51}$ than in the untrained state. Maximum coronary flow has been found to be the same $e^{50}$ or greater than in the untrained state. ${ }^{1822}$ As a result, coronary flow reserve has been either normal $^{5052}$ or supranormal. ${ }^{182251}$ The studies which showed no increase in coronary flow reserve, however, employed training regimes of only 4-12 weeks, while those that involved longer exercise training programmes (16-22 weeks) clearly showed increased pharmacological sensitivity to adenosine in the trained state. ${ }^{19} 22$ The effects in animals of years of intensive training - such as endurance athletes undergo-are unknown.

\section{ECHOCARDIOGRAPHY}

Echocardiographic indices of left ventricular wall thickness and left ventricular mass were similar to published data from normal ${ }^{53}$ and athletic individuals. ${ }^{54}$ Interventricular septal thickness was greater among the athletes but did not exceed $13 \mathrm{~mm}$ in any individual. Internal ventricular diameter was a mean of $9.2 \%$ greater among the athletes - similar to the 10\% reported by Maron. ${ }^{55}$ Left ventricular mass and left ventricular mass index were therefore sub- stantially greater among the athletes, but only 12 of $26(46 \%)$ met Devereux's criteria for left ventricular hypertrophy. ${ }^{35}$ Data on the prevalence of left ventricular hypertrophy in athletes vary, but the most comprehensive study found physiological hypertrophy only in a minority. ${ }^{56}$

Distal LAD diameter and blood flow were adequately visualised in $93 \%$ of the athletesa higher proportion than previously reported. ${ }^{6} 305758$ This success rate reflects the youth and lean upper body mass of the athletes, which made them ideal echocardiographic subjects.

CORONARY FLOW RESERVE

Resting distal LAD flow was lower in the athletes, while hyperaemic flow was greater. Coronary flow reserve was therefore significantly greater among the athletes. One of the main factors mediating this increased coronary flow reserve is the resting bradycardia. For a given individual, if "resting" heart rate is increased above baseline by pacing, resting coronary flow increases while hyperaemic flow is unchanged. Coronary flow reserve therefore diminishes linearly with increasing resting heart rate..$^{59-62}$ Extrapolation of this observation below normal resting heart rates would suggest that resting bradycardia might augment coronary flow reserve, and certainly sedentary pigs subject to long term pacing induced bradycardia do show reduced resting coronary blood flow in comparison with sham operated controls. ${ }^{38}$ Resting bradycardia is therefore likely to account for some of the observed increase in coronary flow reserve.

Hyperaemic flow in athletes is increased, but this increase is negated by scaling for left ventricular mass. This might suggest that there is not a genuine increase in peak myocardial vascular capacity in trained individuals, rather that hyperaemic flow for a given area of myocardium remains maximal and is unaffected by exercise training. Histopathological analysis of myocardial structure in exercise trained animals, however, has - with a couple of exceptions ${ }^{39}{ }^{50}$ - provided evidence of increased myocardial capillary density. ${ }^{63-67}$ Despite this, not all animal studies have shown an increase in maximum coronary flow per unit mass in the trained state, and therefore any relation between myocardial capillary density and maximum coronary flow remains conjectural.

INFLUENCE OF THE ENDOTHELIUM

Enhanced endothelium dependent coronary vasodilatation, ${ }^{20}{ }^{68-70}$ and enhanced endothelium independent coronary vasodilatation ${ }^{18} 1921226971$ have both been found in exercise trained animals. More recent human studies have suggested increased endothelium dependent vasodilatation in response to training. ${ }^{72} 73$ Our work supports the concept of augmented endothelium independent coronary vasodilatation in the trained state.

INFLUENCE OF HYPERTROPHY

Coronary flow reserve is impaired in pathological hypertrophy ${ }^{12}$ 13-17 $^{15}$ owing to coronary 
medial thickening, ${ }^{74}$ increased perivascular collagen, ${ }^{75}$ interstitial fibrosis, ${ }^{76}$ and fibre hypertrophy ${ }^{77}$ We have shown, by contrast, that varying degrees of physiological hypertrophy do not necessarily impair coronary flow reserve in man, and this is corroborated by previous research in greyhounds. ${ }^{78}$ This could prove useful in differentiating athlete's heart-in which coronary flow reserve is in the normal to supranormal range-from hypertrophic cardiomyopathy, in which coronary flow reserve is markedly attenuated. ${ }^{79}$

\section{LIMITATIONS}

In recording blood flow, angles of incidence above $30^{\circ}$ are undesirable as $\cos \theta$ begins to assume greater overall importance (cos $30=0.87$ ). However, in all cases flow was individually angle corrected and therefore the potential significance of this variation was minimised.

Cardiac motion dictated that systolic and diastolic envelopes were not always of equal clarity. Therefore systolic and diastolic velocity-time integral could not always be recorded from identical spectral envelopes.

For a given coronary perfusion pressure (within limits of autoregulation) alterations in aortic pressure produce parallel increases in basal and maximum coronary flow, such that coronary flow reserve remains the same. ${ }^{5960}$ Therefore continuous monitoring of systemic arterial pressure was not undertaken.

Accurate measurement of coronary flow reserve depends on obtaining true resting coronary flow. Echocardiography is relatively unstressful, and certainly less so than coronary angiography, but even in this study true resting flow may not have been achieved in all participants, thus artificially reducing coronary flow reserve.

We could not be absolutely sure that our population samples did not include subjects with minor coronary disease or abnormalities, but short of undertaking intravascular ultrasound, a guarantee of this nature was not possible, and adequate precautions were taken to avoid inclusion of those with possible cardiovascular disease. As this was a non-invasive study, we were at least able to avoid the unsatisfactory option of recruiting patients with chest pain but angiographically normal coronary arteries - a practice that has been fairly criticised. ${ }^{80}$

\section{CONCLUSIONS}

Coronary flow reserve in endurance athletes is supranormal, largely as a result of diminished resting coronary flow rather than augmented hyperaemic coronary flow. The increase in distal LAD diameter with sublingual glyceryl trinitrate was greater in athletes than controls, suggesting that endothelium independent vasodilatation is enhanced by exercise training. Pathological hypertrophy is known to limit coronary flow reserve, but physiological hypertrophy does not have the same effect. Hypertrophy of the myocardium on its own therefore does not necessarily impair coronary flow reserve. Adenosine transthoracic echocardio- graphy continues to be a promising technique for investigating coronary flow reserve.

DJRH-S was supported by a British Heart Foundation Junior Fellowship.

1 Gould KL, Lipscomb K. Effects of coronary stenoses on coronary flow reserve and resistance. Am 7 Cardiol 1974;34:48-55.

2 Wilson RF, Laughlin DE, Ackell PH, et al. Transluminal, subselective measurement of coronary artery blood flow velocity and vasodilator reserve in man. Circulation 1985;72:82-92.

3 Dayanikli F, Grambow D, Muzik O, et al. Early detection of abnormal coronary flow reserve in asymptomatic men at high risk for coronary artery disease using positron emission tomography. Circulation 1994;90:808-17.

4 Hundley WG, Lange RA, Clarke GD, et al. Assessment of coronary arterial flow and flow reserve in humans with magnetic resonance imaging. Circulation 1996;93:1502-8.

5 Iliceto S, Marangelli V, Memmola C, et al. Transesophageal Doppler echocardiography evaluation of coronary blood low velocity in baseline conditions and during 1991;83:61-9.

6 Ross JJ, Mintz GS, Chandrasekaran K. Transthoracic wo-dimensional high frequency (7.5 MHz) ultrasonic visualization of the distal left anterior descending coronary artery. F Am Coll Cardiol 1990;15:373-7.

7 Fusejima K. Noninvasive measurement of coronary artery blood flow using combined two-dimensional and Doppler echocardiography. $\mathcal{F}$ Am Coll Cardiol 1987;10:1024-31.

8 Hildick-Smith DJR, Shapiro LM. Potential use of transthoracic echocardiography in the assessment of coronary flow reserve. F Am Soc Echocardiogr 1999;12:590-5.

9 Hozumi T, Yoshida K, Ogata Y, et al. Noninvasive assessment of significant left anterior descending coronary artery stenosis by coronary flow velocity reserve with transthoracic color Doppler echocardiography. Circulation 1998; 97:1557-62.

10 Hozumi T, Yoshida K, Akasaka T, et al. Noninvasive assessment of coronary flow velocity and coronary flow velocity ment of coronary flow velocity and coronary flow velocity
reserve in the left anterior descending coronary artery by reserve in the left anterior descending coronary artery by nique. f Am Coll Cardiol 1998;32:1251-9.

11 Caiati C, Montaldo C, Zedda N, et al. New noninvasive method for coronary flow reserve assessment: contrastenhanced transthoracic second harmonic echo Doppler. Circulation 1999;99:771-8

12 Pichard AD, Smith H, Holt J, et al. Coronary vascular reserve in left ventricular hypertrophy secondary to chronic aortic regurgitation. Am f Cardiol 1983;51:315-20.

13 Marcus ML, Doty DB, Hiratzka LF, et al. Decreased coronary reserve: a mechanism for angina pectoris in patients with aortic stenosis and normal coronary arteries. $N$ Engl F Med 1982;307:1362-6.

14 Alyono D, Anderson RW, Parrish DG, et al. Alterations of myocardial blood flow associated with experimental canine left ventricular hypertrophy secondary to valvular aortic stenosis. Circ Res 1986;58:47-57.

15 Nitenberg A, Foult JM, Antony I, et al. Coronary flow and resistance reserve in patients with chronic aortic regurgitation, angina pectoris and normal coronary arteries. $¥ \mathrm{Am}$ tion, angina pectoris and nordiol 1988;11:478-86.

16 Opherk D, Mall G, Zebe H, et al. Reduction of coronary reserve: a mechanism for angina pectoris in patients with arterial hypertension and normal coronary arteries. Circulation $1984 ; 69: 1-7$.

17 Choudhury L, Rosen SD, Patel D, et al. Coronary vasodilator reserve in primary and secondary left ventricular hypertrophy. A study with positron emission tomography. Eur Heart f 1997;18:108-16.

18 DiCarlo SE, Blair RW, Bishop VS, et al. Daily exercise enhances coronary resistance vessel sensitivity to pharmacological activation. F Appl Physiol 1989;66:421-8.

19 Oltman CL, Parker JL, Adams HR, et al. Effects of exercise training on vasomotor reactivity of porcine coronary arteries. Am $\mathcal{F}$ Physiol 1992;263:H372-82.

20 Mombouli JV, Nakashima M, Hamra M, et al. Endotheliumdependent relaxation and hyperpolarization evoked by bradykinin in canine coronary arteries: enhancement by exercise-training. Br $\mathcal{F}$ Pharmacol 1996;117:413-18.

21 Laughlin MH. Effects of exercise training on coronary transport capacity. $\mathcal{F}$ Appl Physiol 1985;58:468-76.

22 Laughlin MH, Overholser KA, Bhatte MJ. Exercise training increases coronary transport reserve in miniature swine. $\mathcal{f}$ Appl Physiol 1989;67:1140-9.

23 Bird S, Davison R, eds. Physiological testing guidelines, 3rd ed. Leeds: British Association of Sport and Exercise Sciences, 1997.

24 Smits P, Lenders JW, Thien T. Caffeine and theophylline attenuate adenosine-induced vasodilation in humans. Clin Pharmacol Ther 1990;48:410-18.

25 Jost S, Rafflenbeul W, Reil GH, et al. Reproducible uniform coronary vasomotor tone with nitrocompounds: prerequisite of quantitative coronary angiographic trials. Cathet Cardiovasc Diagn 1990;20:168-73.

26 Wilson RF, White CW. Intracoronary papaverine: an ideal coronary vasodilator for studies of the coronary circulation in conscious humans. Circulation 1986;73:444-51.

27 Sahn DJ, DeMaria A, Kisslo J, et al. Recommendations regarding quantitation in M-mode echocardiography: 

results of a survey of echocardiographic measurements.

28 Devereux RB, Reichek N. Echocardiographic determination of left ventricular mass in man. Anatomic validation of the method. Circulation 1977;55:613-18.

29 Drexler H, Zeiher AM, Wollschlager H, et al. Flowdependent coronary artery dilatation in humans. Circula tion 1989;80:466-74.

30 Hildick-Smith DJR, Shapiro LM. Transthoracic echocardiographic measurement of coronary artery diameter: validation against quantitative coronary angiography. $7 \mathrm{Am} \mathrm{Soc}$ Echocardiogr 1998;11:893-7.

31 Streeter VL. Viscous effects: fluid resistance. Fluid mechanics, 5th ed. New York: McGraw-Hill, 1971:240-51.

32 Doucette JW, Corl PD, Payne HM, et al. Validation of a Doppler guide wire for intravascular measurement of coronary artery flow velocity. Circulation 1992;85:1899coron
Sudhir

33 Sudhir K, MacGregor JS, Barbant SD, et al. Assessment of coronary conductance and resistance vessel reactivity in response to nitroglycerin, ergonovine and adenosine: in response to nitroglycerin, ergonovine and adenosine: in
vivo studies with simultaneous intravascular twovivo studies with simultaneous intravascular two-
dimensional and Doppler ultrasound. $₹ \mathrm{Am}$ Coll Cardiol dimensional and

34 Du Bois D, Du Bois EF. A formula to estimate the approximate surface area if height and weight be known. Arch Intern Med 1916;17:863-71

35 Devereux RB. Detection of left ventricular hypertrophy by M-mode echocardiography. Anatomic validation, standardization, and comparison to other methods. Hypertension 1987;9:19-26.

36 Kern MJ, Deligonul U, Tatineni S, et al. Intravenous adenosine: continuous infusion and low dose bolus administration for determination of coronary vasodilator reserve in patients with and without coronary artery disease. $\mathcal{F} \mathrm{Am}$ Coll Cardiol 1991;18:718-29.

37 Wilson RF, Wyche K, Christensen BV, et al. Effects of adenosine on human coronary arterial circulation. Circulation 1990;82:1595-606.

38 Brown MD, Davies MK, Hudlicka O. The effect of long-term bradycardia on heart microvascular supply and long-term bradycardia on heart microvascular sup
performance. Cell Mol Biol Res 1994;40:137-42.

39 Laughlin MH, Tomanek RJ. Myocardial capillarity and maximal capillary diffusion capacity in exercise-trained dogs. F Appl Physiol 1987;63:1481-6.

40 Dickhuth HH, Lehmann M, Auch Schwelk W, et al. Physical training, vegetative regulation, and cardiac hypertrophy. f Cardiovasc Pharmacol 1987;10(suppl 6):S71-8.

41 Heiss HW, Barmeyer J, Wink K, et al. Studies on the regulation of myocardial blood flow in man. I. Training effects on blood flow and metabolism of the healthy heart at rest and during standardized heavy exercise. Basic Res Cardiol 1976; 71:658-75.

42 Haskell WL, Sims C, Myll J, et al. Coronary artery size and dilating capacity in ultradistance runners. Circulation 1993; 87:1076-82.

43 Radvan J, Choudhury L, Sheridan DJ, et al. Comparison of coronary vasodilator reserve in elite rowing athletes versus
hypertrophic cardiomyopathy. Am f Cardiol 1997;80:1621hypert

44 Toraa M, Pouillard F, Merlet P, et al. Cardiac hypertrophy and coronary reserve in endurance athletes. Can $\mathcal{F} A p p l$ Physiol 1999;24:87-95.

45 Nitenberg A, Antony I. Coronary vascular reserve in humans: a critical review of methods of evaluation and of interpretation of the results. Eur Heart f 1995;16(supp I):7-21.

46 Currens J, White P. Half a century of running: clinical, physiologic and autopsy findings in the case of Clarence De Mar, "Mr. Marathoner". N Engl f Med 1961;265:988-93.

47 Leon AS, Bloor CM. Effects of exercise and its cessation on the heart and its blood supply. $\mathcal{F}$ Appl Physiol 1968;24:48590.

48 Pelliccia A, Spataro A, Granata M, et al. Coronary arteries in physiological hypertrophy: echocardiographic evidence of increased proximal size in elite athletes. Int 7 Sports Med 1990;11:120-6.

49 Zeppilli P, Merlino B, Vannicelli R, et al. Coronary arteries and athlete's heart. Arch Mal Coeur Vaiss 1989;82 (Spec No 2):89-92.

50 Breisch EA, White FC, Nimmo LE, et al. Exercise-induced cardiac hypertrophy: a correlation of blood flow and microvasculature. F Appl Physiol 1986;60:1259-67.

51 Laughlin MH, Diana JN, Tipton CM. Effects of exercise training on coronary reactive hyperemia and blood flow in the dog. F Appl Physiol 1978;45:604-10

52 Carey RA, Santamore WP, Michele JJ, et al. Effects of endurance training on coronary resistance in dogs. Med Sci Sports Exerc 1983;15:355-9.

53 Devereux RB, Lutas EM, Casale PN, et al. Standardization of $\mathrm{M}$-mode echocardiographic left ventricular anatomic measurements. $\mathcal{F}$ Am Coll Cardiol 1984;4:1222-30.
54 Shapiro LM. Physiological left ventricular hypertrophy. $\mathrm{Br}$ Heart f 1984;52:130-5.

55 Maron BJ. Structural features of the athlete heart as defined by echocardiography. F Am Coll Cardiol 1986;7:190-203.

56 Pelliccia A, Maron BJ, Spataro A, et al. The upper limit of physiologic cardiac hypertrophy in highly trained elite athletes. $N$ Engl F Med 1991;324:295-301.

57 Kenny A, Shapiro LM. Transthoracic high-frequency two-dimensional echocardiography, Doppler and color flow mapping to determine anatomy and blood flow patterns in the distal left anterior descending coronary artery. Am f Cardiol 1992;69:1265-8.

58 Crowley JJ, Shapiro LM. Noninvasive analysis of coronary artery poststenotic flow characteristics by using transthoracic echocardiography. F Am Soc Echocardiogr 1998;11:19.

59 Rossen JD, Winniford MD. Effect of increases in heart rate and arterial pressure on coronary flow reserve in humans. $\mathcal{F}$ Am Coll Cardiol 1993;21:343-8.

60 McGinn AL, White CW, Wilson RF. Interstudy variability of coronary flow reserve. Influence of heart rate, arterial pressure, and ventricular preload. Circulation 1990;81: 1319-30.

61 Cleary RM, Ayon D, Moore NB, et al. Tachycardia, contractility and volume loading alter conventional indexes of coronary flow reserve, but not the instantaneous hyperemic flow versus pressure slope index. I Am Coll Cardiol 1992;20:1261-9.

62 Hongo M, Nakatsuka T, Watanabe N, et al. Effects of heart rate on phasic coronary blood flow pattern and flow reserve in patients with normal coronary arteries: a study with an intravascular Doppler catheter and spectral analysis. Am Heart f 1994; 127:545-51.

63 Ljungqvist A, Unge G. Capillary proliferative activity in myocardium and skeletal muscle of exercised rats. F Appl
Physiol 1977; 43:306-7.

64 Wyatt HL, Mitchell J. Influences of physical conditioning and deconditioning on coronary vasculature of dogs. $\mathcal{F} A p p l$ Physiol 1978;45:619-25.

65 Brown MD, Davies MK, Hudlicka O, et al. Long term bradycardia by electrical pacing: a new method for studying heart rate reduction. Cardiovasc Res 1994;28:1774-9.

66 Tomanek RJ, Torry RJ. Growth of the coronary vasculature in hypertrophy: mechanisms and model dependence. Cell Mol Biol Res 1994;40:129-36.

67 Hudlicka O, Brown MD, Walter $\mathrm{H}$, et al. Factors involved in capillary growth in the heart. Mol Cell Biochem 1995;147: 57-68.

68 Wang J, Wolin MS, Hintze TH. Chronic exercise enhances endothelium-mediated dilation of epicardial coronary artery in conscious dogs. Circ Res 1993;73:829-38.

69 Parker JL, Oltman CL, Muller JM, et al. Effects of exercise training on regulation of tone in coronary arteries and arterioles. Med Sci Sports Exerc 1994;26:1252-61.

70 Muller JM, Myers PR, Laughlin MH. Vasodilator responses of coronary resistance arteries of exercise-trained pigs. Circulation 1994;89:2308-14.

71 Buttrick PM, Schaible TF, Scheuer J. Combined effects of hypertension and conditioning on coronary vascular reserve in rats. F Appl Physiol 1986;60:275-9.

72 Clarkson P, Montgomery HE, Mullen MJ, et al. Exercise training enhances endothelial function in young men. $f \mathrm{Am}$ Coll Cardiol 1999;33:1379-85.

73 Hambrecht R, Wolf A, Gielen S, et al. Effect of exercise on coronary endothelial function in patients with coronary artery disease. N Engl $\mathcal{F}$ Med 2000;342:454-60.

74 Tomanek RJ. Response of the coronary vasculature to myocardial hypertrophy. 7 Am Coll Cardiol 1990;15:528-33.

75 Ito N, Isoyama S, Takahashi T, et al. Coronary dilator reserve and morphological changes after relief of pressureoverload in rats. $\mathcal{F}$ Mol Cell Cardiol 1993;25:3-14.

76 Villari B, Vassalli G, Monrad ES, et al. Normalization of diastolic dysfunction in aortic stenosis late after valve replacement. Circulation 1995;91:2353-8.

77 Krayenbuehl HP, Hess OM, Schneider J, et al. Physiologic or pathologic hypertrophy. Eur Heart ff 1983;4(suppl A):29-34

78 Cohen MV. Coronary vascular reserve in the greyhound with left ventricular hypertrophy. Cardiovasc Res 1986;20: 182-94.

79 Camici P, Chiriatti G, Lorenzoni R, et al. Coronary vasodilation is impaired in both hypertrophied and nonhypertrophied myocardium of patients with hypertrophic cardiomyopathy: a study with nitrogen-13 ammonia and positron emission tomography. $\mathcal{F}$ Am Coll Cardiol 1991;17: 879-86.

80 Marcus ML, White CW. Coronary flow reserve in patients with normal coronary angiograms. F Am Coll Cardiol 1985; 6:1254-6. 